\title{
Fair unemployment compensation and the target for egalitarian concerns
}

\section{Cornelius Cappelen}

If we want to make people more equal, what should we make them more equal in? For example, should it be resources, such as income, or should it be subjective well-being, such as preference satisfaction? The aim of this article is to critically examine the two main answers to this question within a luck egalitarian moral framework, which is a framework that aims to eliminate inequalities caused by non-responsibility factors, while preserving inequalities due to responsibility factors. I argue that the arguments typically presented in favor of equalizing incomes rather than subjective well-being are weak and that within a luck egalitarian moral framework the claim that resources and not welfare should be considered the appropriate basis for interpersonal comparisons is in need of justification.

The question of what society should equalize is applied to the issue of what should be the fair level of unemployment insurance compensation: Should we only compensate the involuntary unemployed for the income loss associated with unemployment, or also for the non-pecuniary costs associated with unemployment? The answer to this question, I argue, depends on where the cut between responsibility factors and non-responsibility factors is drawn.

Keywords: unemployment insurance, equality, responsibility, redistribution, fairness, interpersonal comparison

\section{Introduction $^{1}$}

The purpose of redistributive policies, such as unemployment insurance (UI) compensation, is to make people more equal. But what is it that society should aim at equalizing? Should it be resources, such as income and 
wealth, or should it be some conception of subjective well-being, such as preference satisfaction?

In order to illustrate how this question might have practical relevance, I will consider the numerous studies that document the destructive effect of unemployment on people's subjective well-being (see e.g. Warr 1987; Whelan et al. 1991; Gallie \& Russell 1998). It is clearly understood in the literature that the negative effect of unemployment on well-being goes well beyond the effect that the income loss associated with the unemployment can bring about. Indeed, the non-financial costs of unemployment seem to exceed the financial costs by far (given that the UI compensation level reaches a minimum threshold). The fair level of unemployment compensation is therefore highly affected by whether the unemployed should be compensated for income losses only, or also for welfare losses.

In Norway (as in most other countries) the calculation of UI benefits is earnings related and the unemployed are only compensated for income losses (the replacement rate is approximately 64 percent). Any loss of subjective well-being associated with unemployment is therefore not compensated for. In this article I examine whether or not this is fair given that we want to respect two normative intuitions that have proven to have strong appeal in Western societies, namely what we may refer to as the egalitarian intuition and the liberal intuition. ${ }^{2}$ The egalitarian intuition is that we should aim at eliminating those inequalities between individuals that are caused by factors they are not responsible for (non-responsibility factors). The liberal intuition is that we are justified in preserving inequalities between individuals that are caused by factors they are responsible for (responsibility factors).

I argue that if we rely on the two intuitions as guiding ideals in the design of social policies, the question of what should be the appropriate basis for interpersonal comparisons depends on where we draw the line between responsibility factors and non-responsibility factors. Arguments in favor of both welfare and resources will be examined, and I will consider the implications the various arguments have for the issue of fair unemployment compensation. My objective is not to defend a particular position, but rather to survey the two main contributions, represented by Cohen and Dworkin, respectively. However, I do argue that the arguments typically presented in favor of equalizing resources rather than subjective well-being are weak and that within a luck egalitarian moral framework the claim that resources and not welfare should be considered the appropriate basis for interpersonal comparisons is still in need of justification. From this I conclude that we may have reasons to raise the unemployment compensation level in Norway.

The article is organized as follows. I first give a brief introduction to luck egalitarian ethics, which are the ethics that have been applied in studies of 
the distributive implications of combining egalitarian intuition with liberal intuition. I then present the two main luck egalitarian positions on where the responsibility cut should be drawn, starting with Dworkin's cut before presenting Arneson and Cohen's cut. Arneson and Cohen's cut was developed as a response to Dworkin's cut and as one that is truer to the distinction they believe motivates Dworkin: the arbitrariness of (brute) luck and the significance of choice. Dworkin still maintains that his own cut is superior to Arneson and Cohen's cut, and I will examine some of Dworkin's responses to Arneson and Cohen's criticism.

\section{Luck egalitarian ethics}

We often judge when it is fair for society compensate people for the disadvantages of their situation, and when it is fair that the individuals themselves must bear these disadvantages. In making such judgements it is common to make an important distinction between disadvantages that are a result of factors people themselves are responsible for and disadvantages that are a result of factors people are not responsible for. For example, most people share the intuition that when someone is disadvantaged due to bad brute luck, i.e. when someone themselves is not to blame for their own disadvantage, then society has an obligation help them. However, most people also believe that society has no similar obligation if the disadvantage is a direct result of her own choices. Such judgements play a key role in the evaluation of unemployment policies. Unemployment policies are seen as fair when they compensate involuntarily unemployed individuals, who cannot be blamed for being unemployed; however, they are seen as unfair if they also compensate people who are unemployed due to choice.

Theories of justice that incorporate the idea that redistribution policies must make a key distinction between inequalities that people should be seen as responsible for and inequalities that people should not be seen as responsible for may be referred to as luck egalitarian theories of justice (e.g., Dworkin 1981a, 1981b, 2000; Arneson 1989, 1990; Cohen 1989; Roemer 1993, 1996; Fleurbaey 1995, 2008). ${ }^{3}$ A common feature of luck egalitarian theories of justice is that they draw a distinction between factors individuals should be held responsible for, responsibility factors, and factors individuals should not be held responsible for, non-responsibility factors. For a given cut between these factors (i.e., we have decided which factors people are responsible for and which they are not responsible for), luck egalitarian theory can be seen to incorporate the egalitarian and liberal intuitions introduced above: inequalities due to factors for which the agent is not responsible are unjust and should be eliminated (the egalitarian intuition), 
while inequalities due to factors for which the agent is responsible are just and should be preserved (the liberal intuition).

If the luck egalitarian framework is to give guidance in the design of redistributive policies it is necessary to answer a central question: Where should we draw the line between responsibility factors and non-responsibility factors? Where we draw this line is essential for two reasons. Firstly, it affects the ideal level of redistribution. Noting the implications of the luck egalitarian framework in two extreme cases will most easily reveal this. No redistribution would be justifiable if all factors affecting individual outcomes were responsibility factors, while ideally one should aim at equalizing outcomes completely if all factors affecting individual outcomes are nonresponsibility factors. ${ }^{4}$ Secondly, where the responsibility cut is drawn also affects what should be considered the appropriate basis for interpersonal comparisons. (Given that we want to make people more equal, what is it that we should make people more equal in?)

It is the latter aspect that will concern me in this article. To make the question more concrete and politically relevant, consider a person who experiences income loss due to involuntary unemployment. The fact that she is involuntarily unemployed causes her to have fewer resources, i.e., less labour income, than those who are not involuntary unemployed and who choose to work. But this is not the only inequality that involuntary unemployment causes. As already emphasized, it has been proven that the nonpecuniary cost associated with unemployment is high for many involuntary unemployed individuals, and that even with full income-loss compensation involuntarily unemployed individuals have, on average, a lower level of subjective well-being than people who work. Should society also compensate for these non-pecuniary losses, or should it only aim at equalizing income inequalities?

In the next two sections I present the two dominant answers to this question within a luck egalitarian moral framework, starting with Dworkin's view that society should only aim at eliminating inequalities in resources because people are responsible for their own level of psychological wellbeing (given a fair distribution of resources, such as income and wealth).

\section{Dworkin's responsibility cut}

In 1981 Ronald Dworkin published two highly influential articles on distributive justice subtitled «Equality of welfare» (1981a) and «Equality of resources» (1981b). In these articles he distinguished two ways in which we may compare different people's situations. On the one hand, we might compare the resources each has available, such as income and wealth; on the other hand, we might compare the welfare (utility) that each has achieved 
with whatever resources she has available. The question Dworkin addressed is which of these two positions should be considered the most suitable target for our egalitarian concern. In other words, if we want to render people more equal, for whatever reason, then what should we render them more equal in? Should it be subjective well-being, or income and wealth?

Dworkin's well-known answer was that it should be income and wealth; but more important than his answer was the many responsibility considerations he presented in favor of it. Dworkin makes a crucial distinction within a broad category of personal qualities: between a person's personality, understood in a broad sense to include her tastes, character, convictions, preferences, motives, and ambitions, on the one hand, and her personal resources of health, strength, mental ability, and the innate capacity to produce goods that others will pay to have (talent), on the other. He further claims that a political community should aim to erase or mitigate differences between people in their personal resources, but should not aim to mitigate or compensate for differences in personality, since a person is responsible for her personality but not for her personal resources. In addition, external factors such as race, gender, parental income, and other matters of «brute luck» fall on the non-responsibility side of the cut according to Dworkin, and so the correct place to draw the responsibility cut is between a person's personality and the choices that flow from it, which are considered to be responsibility factors, on the one hand, and personal and external resources on the other hand, which are considered to be non-responsibility factors (see e.g. Sovereign Virtue, Dworkin 2000: 81).

The crucial idea behind Dworkin's proposal is his assumption that in order to be ascribed responsibility for personality traits (and choices that follow from them) the traits need to be genuine personality traits, i.e., genuine preferences. This is a criterion of authenticity, excluding whimsical fancies, addictions, and ill-formed desires. Dworkin admits that this distinction between genuine preferences on the one hand, and what he calls cravings on the other hand, might be hard to draw in certain cases, but the idea is that people are responsible for genuine personality traits, but not for cravings.

The claim that we should hold people responsible for their personalities but not for their personal and external resources has an immediate implication for what should be deemed appropriate as a basis for interpersonal comparison according to Dworkin. ${ }^{5}$ People's personality traits, such as their preferences and tastes, are usually those that are deemed relevant for distributive evaluation on welfare-based theories of justice (such as utilitarianism and equality of welfare). ${ }^{6}$ However, since people are responsible for their personality traits on Dworkin's account of justice, it is simply unfair to tailor distributive shares so as to reach a final pattern of welfare distribution. For example, if one individual has expensive preferences (e.g., she prefers fine 
champagne over beer) and another cheap preferences (e.g., she prefers beer over champagne), society should not give more resources to the latter, as utilitarianism prescribes (since she is the most efficient transformer of resources into utility of the two); and neither should it give more resources to the former, as the doctrine of equality of welfare prescribes (since she is the least efficient transformer of resources into utility of the two).

If we apply Dworkin's claims to the issue of unemployment compensation, any non-financial costs associated with being unemployed are to be left uncompensated, since people's level of psychological well-being is considered irrelevant in the evaluation of people's fair shares. We are only permitted to compensate the unemployed on the account that they have less inwork income (fewer resources) than those who work. That the unemployed prefer to work rather than to receive UI compensation (and the fact that they are more dissatisfied with their lives than those who work) is not considered relevant as long as they are properly compensated for their income loss.

\section{Arneson and Cohen's responsibility cut}

In the late 1980s Cohen (1989) and Arneson $(1989,1990)$ proposed a revision of Dworkin's responsibility cut, which is philosophically quite similar. Both proposals share with Dworkin's the general view that distributive justice consists of a restricted kind of egalitarianism: we should erase or mitigate inequalities caused by non-responsibility factors, but preserve inequalities caused by responsibility factors. Both Cohen and Arneson disagree, however, with Dworkin on where to draw the responsibility cut. Dworkin, as we have seen, holds people responsible for their personalitiessuch as tastes, ambitions, and preferences-and he therefore also holds people responsible for the choices that people's personalities trigger. Cohen and Arneson disagree with this responsibility cut by pointing out that the personalities that trigger choice may be «unchosen». In the following quotations are two examples which Dworkin himself puts forth when explaining where Cohen's and Arneson's proposals depart from his own even though they overlap. In the first example they all agree, while in the second example Dworkin's cut differs from Cohen's and Arneson's:

Suppose someone cannot stand the taste of ordinary water from the tap - it tastes unbearably sour to him - and he therefore chooses to buy more expensive bottled water. It is true that he has a choice whether or not to do that. But he did not choose to have the property - a special sensory reaction - that made the choice not to do so distasteful. The psychological condition is bad luck, and he should therefore be compensated for his misfortune: he should be given extra resource so that he will not be 
worse off buying bottled water than others who make do with tap water. (Dworkin 2000: 288)

Here, Dworkin on the one hand, and Arneson and Cohen on the other, agree. According to Dworkin, the sensory reaction is a craving that the individual would happily disown if asked - it is not part of his personality and he should not be held responsible for it. The second example shows where Dworkin on the one hand, and Arneson and Cohen on the other, disagree. Dworkin attributes (rightly) the following view to Arneson and Cohen:

\begin{abstract}
Now suppose someone yearns to be a photographer but finds that if he is to realize his dream he must spend the greater part of his income buying expensive cameras and lenses. Once again, he could choose not to buy the equipment. But that choice would make him miserable, at least for a time, and once again he did not choose to have the ambition that has that consequence. Surely (the critics argue) it is just as unfair to make him bear the consequential responsibility for his choice to buy the equipment as it would be to make someone handicapped in some other way - born blind or without talent or unable to stand tap water - bear the financial consequences of that condition. (Dworkin 2000: 288)
\end{abstract}

Contrary to Arneson and Cohen, Dworkin claims that the aspiring photographer should bear the actual consequences of buying expensive lenses and cameras because photography is part of his personality-it is something he likes and that he would not switch for a less expensive hobby.

The fundamental responsibility cut, according to Cohen and Arneson, is between those factors a person cannot control and those factors she can control. In the following, I will draw attention to certain aspects of Cohen's view, which is very similar to Arneson's. ${ }^{7}$ Although Dworkin did not highlight the notion of choice in particular in his 1981 articles (he spoke mostly of personality traits such as ambitions and preferences which trigger choice), Cohen argued that giving variable treatment to personality traits on the one hand and resources on the other is only reasonable if the former is chosen while the latter is unchosen. But personality traits might be just as unchosen as resources, according to Cohen. ${ }^{8}$ Thus, the crucial distinction for Cohen is between chosen and unchosen circumstances (chance) rather than personality and resources:

The right reading of egalitarianism [...] is to eliminate disadvantage, by which I (stipulatively) mean disadvantage for which the sufferer cannot be made responsible, since it does not appropriately reflect choices that he has made or is making or would make. (Cohen 1989: 916)

The difference between Dworkin's cut and Cohen's cut is crucial since Cohen's cut transforms luck egalitarianism into a welfare-based theory of justice. To give an example: if people's tastes were assumed to be nonresponsibility factors because they are in general unchosen, we would need 
to eliminate (according to Cohen's view) inequalities in welfare arising from someone having more expensive tastes than others. A person who has expensive tastes is less efficient in transforming resources, for example, income, into ingredients of a successful life than a person with inexpensive tastes, and this inequality is unfair and should be eliminated in those situations where it is unreasonable to hold people responsible for their tastes; i.e., if a person's tastes are involuntarily developed or if it could be proved that the person's expensive tastes are just features of her neural system and that it is purely accidental that she is satisfied by fine champagne rather than by cheap beer. Dworkin, on the other hand, holds people responsible for their tastes independently of whether they have chosen them or not, and inequalities in welfare that originate from differences in tastes (or other character traits) are therefore unproblematic for Dworkin. Thus, while Cohen's cut compensates for both welfare and resource disadvantages (when they are not genuinely chosen), there is no room at all in Dworkin's theory for equality of welfare. It focuses only on one dimension of shortfall: people's personal and external resources. Cohen believes this one-dimensional focus fails to capture the significance of choice and the arbitrariness of (brute) luck that he believes motivates Dworkin's project.

Cohen's (and Arneson's) claim that people should be compensated for unchosen welfare disadvantages implies that as long as a person is involuntary unemployed and cannot be blamed for any welfare loss associated with being out of work, she should be compensated for her welfare loss in addition to her financial loss. In other words, in the calculation of a person's fair level of UI compensation we need to account for how she perceives her own welfare.

Perhaps it is true that Cohen's cut between genuine choice (not dictated by unchosen preferences and within a person's control) and chance (beyond a person's control) more faithfully captures the motivation from which Dworkin begins. But still we are reluctant to accept Cohen's cut, and Cohen himself presents the main reason for this:

Someone might say that to make choice central to distributive justice lands political philosophy in the morass of the free will problem. The distinction between preferences and resources is not metaphysically deep, but it is, by contrast, awesomely difficult to identify what represents genuine choice. Replacing Dworkin's cut by the one I have recommended subordinates political philosophy to metaphysical questions that may be impossible to answer.

To that expression of anxiety I have one unreassuring and one reassuring thing to say. The unreassuring thing is that we may indeed be up to our necks in the free will problem, but that is just tough luck. It is not a reason for not following the argument where it goes. (Cohen 1989: 224) 
This metaphysical worry should be taken seriously. If we have to wait for a defensible theory of genuine choice then, as argued by Fleurbaey (2001), political philosophy will be on hold for some time. One could argue that metaphysical discussions about free will and genuine choice bring little of value to the realm of political philosophy and that the distribution of resources in a society should not depend on how moral philosophers address the question of free will. The challenge then, is how we can present a defensible cut between responsibility factors and non-responsibility factors that resist Cohen's straightforward claim that we should «follow the argument where it goes.» Dworkin's reply to Cohen in Sovereign Virtue (2000) is an attempt at doing that, which is independent from the charge of metaphysical darkness.

\section{A critical examination of Dworkin's reply to Cohen ${ }^{9}$}

In Chapter 7 of Sovereign Virtue (2000) (hereafter abbreviated to SV) Dworkin gives us (at least) two arguments for why his own responsibility cut is superior to Cohen's responsibility cut. The first is that Cohen's cut collapses into a type of welfare egalitarianism that Cohen himself disagrees with. The second is that Dworkin's cut conforms to «ordinary morality,» while Cohen's does not. In the following I will examine and criticize each of these arguments.

\section{Cohen's cut collapses into welfare egalitarianism}

As we have seen, Cohen argues that expensive tastes that are voluntarily cultivated are not compensable; only involuntarily developed expensive tastes are compensable. But precisely because Cohen relies on a distinction between voluntarily and involuntarily developed tastes, Dworkin concludes that he also relies on the assumption that people may be free to choose. But, according to Dworkin, the distinction between voluntarily cultivated tastes and involuntarily developed tastes is illusory, because no taste is genuine in the proper sense Cohen must have in mind. A person can school herself into liking expensive wines, but there is always an underlying reason for this that is beyond her control. People's preferences and the choices they trigger are not casually independent of people's culture, history, and circumstances; they are never genuinely chosen in the free spirit that Cohen needs them to be in order to meaningfully distinguish between chosen and unchosen tastes and preferences. Dworkin concludes from this observation that Cohen's theory collapses back into the simple equality of welfare that Cohen himself wants to abandon (the ideal that both volunta- 
rily cultivated expensive tastes and involuntarily developed expensive tastes are compensable).

Dworkin's metaphysical claim that no choice is truly genuine is close to impossible to substantiate, and equally controversial as Cohen's claim that some choices are genuine. But even if Dworkin is right, he has not yet shown that Cohen's theory collapses back into simple equality of welfare. If there exists no such thing as genuine choice, the ideal of welfare equality and Cohen's ideal of equal opportunity for welfare have the same consequences, i.e., incomes should be redistributed such that everyone ends up with the same level of welfare. However, they are still distinct ethical ideals since they would differ with respect to how equal outcomes are justified. The ideal of equality of welfare would, in Dworkin's words, justify equal outcomes because this is what it means to treat people as equals. Cohen's equal opportunity for welfare ideal, on the other hand, would justify equal outcomes because those who are worse off than others are never responsible for being worse off.

\section{Dworkin's cut conforms to ordinary morality}

Dworkin's second defense of his own responsibility cut is that people in their ordinary lives

take consequential responsibility for their own personalities... we do not count the fact that we have reached some moral or ethical conclusions as a matter of brute luck we had no control over. That would be to treat ourselves as dissociated from our personalities rather than identify with them - to treat ourselves as victims bombarded by random mental radiation. We think of ourselves differently - as moral and ethical agents who have struggled our way to the convictions we now find inescapable. (SV p. 290)

In other words, Dworkin appeals to a morality that aims to make sense of people's practice of ethical criticism. We often blame others (and ourselves) for doing 'this' instead of 'that' - for choosing one option over another; and we often praise others and admire their virtues and applaud their choices. These practices of praise and blame fail to make sense if we do not believe that our choices and preferences are genuine, even though we note that there might be complex cultural, psychological, and biological influences that cause our preferences and choices. In this sense we reject metaphysical determinism, even though we may be wrong in doing so; and this is what Dworkin aims to capture with his responsibility cut. We prefer a political ideal that holds people responsible for their personality traits-even the unchosen ones-because our ordinary understanding of morality would collapse if we failed to do so. Dworkin's responsibility cut appeals to «ordi- 
nary morality,» which tends to view positive as well as negative character traits as something for which people are responsible.

In a further elaboration of why ordinary people take responsibility for even unchosen personality traits and the choices they trigger, Dworkin returns to the example of the photographer, and he tries to explain why ordinary people find it fair to hold him responsible for his unchosen taste for photography:

A passionate photographer, it is true, savors the technology and skill of his craft and the exhilaration of capturing light forever, and he might cite these sensations in explanation of his passion. But he savors these in some measure - often in large measure - because they fit so well with other, more general, opinions he has about the value of aesthetic judgment and response, technical mastery, visual insight, and a large variety of other pertinent values, and these more general opinions are in turn drawn from and play into a yet more general picture of the kind of life that is right, if not for everyone, at least for him. None of this need be (or often is) a matter of selfconscious assessment. But a network of interlocking and mutually reinforcing tastes, beliefs, and judgments is nevertheless at work in the photographer's psyche, and that network explains the revulsion he would feel if he were offered a pill that would drain away his interest in his art. It would be just as bizarre for him to call his commitment bad luck as it would be for someone else to describe his loyalty to his friends that way. (Dworkin 2000: 290-291)

Dworkin draws attention to (at least) two aspects of the photographer's personality traits that make it fair not to compensate him for his expensive hobby even though he did not genuinely choose it. Firstly, the different personality traits that triggered his choice of buying expensive camera equipment are interconnected. Secondly, the photographer would not take a pill to get rid of them since he sincerely enjoys photography.

It is not obvious what role the interconnectedness of people's personality traits plays in Dworkin's argument. But arguably this aspect of our «normal» character traits is meant to reveal how most of our choices are different from choices that are a result of mere cravings, such as the need to buy bottled water due to a special sensory reaction. Cravings and obsessions are not part of our personalities and we do not identify with them precisely because they are not a result of an interconnectedness of various tastes, ambitions, preferences, and value judgments that we hold. It therefore makes sense to relieve people of responsibility for choices that are triggered by cravings and obsessions. However, most of our choices are different from this in that they have been triggered by tastes, ambitions, etc., that we identify with precisely because they are interconnected-they are part of our personalities (and together form our personalities) and we are glad we have them and we would not get rid of them as though they were a headache.

The second aspect of the photographer's personality traits that Dworkin highlights as an argument against compensation is that he would not take a 
pill to get rid of his personality traits. More precisely, he would not take a pill to get rid of those character traits that are interconnected and that are therefore not cravings and obsessions for him, such as his desire for photography. And he does not want to take such a pill precisely because he is glad he has his desire for photography.

In other words, we may interpret Dworkin as meaning we should be held responsible for our choices even in situations where our choices are dictated by unchosen personality traits because we normally (sans cravings and obsessions) identify with our personality traits and are glad we have them. And if we are glad we have them, why should we not take responsibility for them; Why should society view some of them as compensable and due to bad brute luck even though we ourselves are glad we have them and would not think of taking a pill to get rid of them? Certainly, according to Dworkin, the prevailing morality is on his side.

It is important to be precise about exactly what Dworkin believes that his arguments prove. His arguments are meant to show that ordinary people take responsibility for their own personality traits, even the unchosen ones (as long as they are not cravings or obsessions). But it becomes clear from Chapter 7 of SV that he uses this empirical claim to support yet another one, namely that welfare should not be deemed an appropriate basis for interpersonal comparisons. More precisely, in Chapter 7 he objects to the normative ideal that favors «equality in people's capacity or capability or opportunity to secure welfare» (Dworkin 2000: 289). It is not the equal opportunity concept that Dworkin objects to, because he himself favors equal opportunity for resources (income and wealth). What Dworkin objects to is the claim that people should have equal opportunity for welfare rather than for his favored resources, and so what he really objects to is the claim that welfare is the appropriate basis for interpersonal comparisons. The first argument he presents against welfare is the one I have presented above, namely that equal opportunity for welfare collapses into equality of welfare rather than equal opportunity for welfare. The second argument, which he spends several pages on and which seems to be his main argument, is that people take responsibility even for their unchosen personality traits. But it does not follow from this claim that equal opportunity for welfare is an inappropriate political ideal, and my aim in the subsequent paragraphs is to demonstrate this.

The belief that responsibility for even unchosen personality traits somehow «excludes» welfare as an appropriate basis for interpersonal comparisons is common in the luck egalitarian literature, and the discussion has often proceeded on the assumption that if Dworkin is right and people are indeed responsible even for their unchosen character traits, then welfare should be excluded; however, if Cohen is right and people are not responsible for their unchosen character traits, then welfare should be included. Put 
differently, it has been implicitly assumed that a person's level of welfare is only a matter of how efficient she is in transforming resources into the ingredients of a successful life (e.g., whether she has expensive preferences or not). But obviously a person's level of welfare is affected by many other factors than how efficient she is in transforming resources into welfare. In the following I elaborate this claim by use of an example from the labor market.

Imagine a society in which the majority of the working age population have a decent job while a minority are involuntary unemployed. The unemployed have no in-work income, and so they are financially worse off than those who work; however, they also experience non-financial costs as a result of being unemployed and would be better off working even though they would be fully compensated financially while unemployed. In this situation Dworkin would claim that justice is served as long as the unemployed are compensated for their income losses. Cohen, however, would claim that justice is not fully served before the unemployed individuals' loss of wellbeing is also compensated for.

For illustrative purposes, let us briefly return to the photographer and his unchosen taste for buying expensive lenses and camera equipment. Dworkin claims that the photographer is not owed any compensation on the grounds that he has less welfare than one who has an inexpensive hobby; and he does so by arguing that the photographer should be held responsible for his taste for photography, even though this taste is itself unchosen. This argument is controversial, but let us nonetheless stipulate that Dworkin is correct. Note, then, that this responsibility argument fails to be applicable to the unemployment example. Dworkin cannot claim that the unemployed are not owed compensation for their relative welfare deficit by arguing that they are responsible for preferring work to non-work and thus responsible for their level of welfare. Responsibility considerations justify inequalities only in those cases where people are different with respect to a responsibility factor; but this is not the case in the unemployment example, where people are identical with respect to the responsibility factors (i.e., their work preferences). ${ }^{10}$

Dworkin could, of course, bite the bullet and simply say that the differences in welfare which no one is responsible for are unproblematic. But this would conflict with his claim that income inequalities should be mitigated as long as they are caused by differences in responsibility factors. What justifies the mitigation of an income inequality, according to Dworkin, is that no one is responsible for it. It is not the nature of income as an egalitarian target that justifies its redistribution, but how unequal shares of it came about: if someone is responsible (is to blame) for having less income than others she is owed no compensation; but if she is not responsible she is owed 
compensation. Why should not this same justification be applicable to welfare inequalities?

Dworkin could claim that the same justification applies, but that welfare inequalities are always caused by differences in responsibility factors (assuming income is fairly distributed). But this is arguably false, as illustrated by the unemployment example. The unemployment example shows that people can have different levels of welfare (i.e., the unemployed have lower levels of welfare than employees) even though they are identical with respect to the responsibility factors (they all prefer work to non-work) and have the same post-tax income. What causes the welfare inequality in the unemployment example is that people differ with respect to a non-responsibility factor (whether or not they work).

Numerous non-responsibility factors cause inequalities in welfare. Perhaps tall people, because of their height, enjoy more welfare than short people, for example. Dworkin simply has to admit that non-responsibility factors sometimes cause welfare inequalities, and he cannot generally appeal to responsibility arguments in order to defend his claim that welfare should be excluded as an appropriate basis for interpersonal comparisons. What he could do is to claim that welfare inequalities that originate from, for example, height differences are not the kind of inequalities that society should be concerned with. More generally, he could argue that not all of the results of the lottery of nature are relevant for justice, but primarily those results that influence one's position and/or opportunities in man-made social circumstances. In other words, there are some individualistic outcomes that are socially irrelevant and need not be compensated for irrespective of personal responsibility, i.e., we need to separate between socially relevant and private matters. But certainly, welfare inequalities resulting from unequal job opportunities are relevant in this sense and for many the subjective wellbeing associated with employment is just as important as income (given that the income is above a satisfying minimum). More generally, welfare inequalities cannot be deemed socially irrelevant merely because their metrics are welfare (e.g., preferences satisfaction, happiness, etc.).

It is worth stressing that what matters for Dworkin is not only access to resources (such as income) but freedom, equal concern, etc. And so Dworkin might find it problematic that some enjoy all the opportunities that work life initiates, while others, such as the involuntarily unemployed, are denied these same opportunities. But the relevant question is how we should compensate those who for some reason cannot work, given that the ideal of equal work opportunity is yet to be achieved. And Dworkin's answer is that the unemployed should be compensated for income losses only, not for welfare losses. I have argued why I believe that this does not follow from his initial claim that people take responsibility for their even unchosen personality traits. This does not prove, obviously, that equal opportunity for 
welfare is an improper political ideal, only that Dworkin has yet to present a convincing argument for such a view that is coherent with his main argument for why equal opportunity for resources is superior to equal opportunity for welfare. If it were the case that no such argument could be found within a luck egalitarian moral framework, typical OECD UI schemes, including the Norwegian one, are not generous enough since they only compensate the unemployed for income shortfalls, and not for other shortfalls such as welfare deficiencies.

Finally, it is worth stressing that many actual redistribution schemes (although not unemployment compensation) often compensate people because they have a lower level of welfare than other people. For example, it is a practice that we often compensate for poor job quality. People who, for example, work nightshifts receive higher salaries than people who work normal hours, everything else being equal. And garbage workers earn on average more than people in other non-skilled occupations precisely because of the low job-quality. Most people find such compensation to be fair, and so if we may rightfully justify a moral practice by appealing to "ordinary» morality-which Dworkin indicates that we may since he frequently does so in order to defend his claim that people should be held responsible for even their unchosen personality traits-then some welfare inequalities originating from differences in job quality should in fact be eliminated.

\section{Conclusion}

If we believe that Cohen (and Arneson too) is correct, then the fair level of UI compensation goes beyond merely compensating the involuntarily unemployed for their income losses; society also needs to compensate the involuntarily unemployed for the non-financial costs associated with unemployment, such as loss of subjective well-being. If Dworkin is correct, justice is served as long as the unemployed are compensated for their financial costs.

Cohen's ideal that we should compensate the unemployed for welfare losses that are beyond their control may be criticized on the account that it is difficult to implement in a second-best context where society lacks relevant information about people's welfare. Many political theorists, such as John Dunn (1990) and Joseph Carens (2000), believe that normative theorizing must be integrated with an appreciation of the empirical realities of one's society. Is it at all possible to implement Cohen's general ideal that people should have equal opportunity for welfare, and to apply it to the issue of unemployment compensation? 
Even though the literature has proven that the non-pecuniary cost associated with unemployment often is high for many individuals, there will still be individuals who experience a non-pecuniary gain from unemployment. These individuals should rightfully receive less in UI compensation under Cohen's account of justice, than under Dworkin's account. More generally, given Cohen's responsibility cut, the fair UI compensation level that we owe people depends on their level of subjective well-being. We would therefore need to set up institutions that could effectively gather and deploy information that would be necessary in order to carry out this ideal. There are some major obstacles to the setting up of such institutions; for example, unemployed individuals would have incentives to lie about their welfare in order to receive a higher level of UI compensation than they are rightfully entitled to. Such institutions would also be very expensive, raising the administrative costs associated with unemployment insurance.

It should also be noted there are many considerations behind the design of social policies. Luck egalitarianism is a theory about fairness. However, UI, as other social insurance programs, generally runs the risk of purchasing fairness at the cost of distortion. More specifically, UI protects the individual against an unfair and undesirable low level of income during spells of unemployment, and from the need to accept a job when additional searching would be adequately productive. But on the other hand, UI can also distort incentives that cause inefficient use of resources, for example unproductive long job-searches (see e.g. Classen 1979; Solon 1985; Atkinson \& Micklewright 1991; Krueger \& Meyer 2002). An important objective is therefore to balance fairness considerations against incentive considerations. With these observations in mind it can be argued that Cohen's responsibility cut, and the ideal that for example involuntary unemployed individuals should receive in benefits an amount that would eliminate all welfare losses associated with being unemployed, is too generous in the sense that it may create huge distortions and an unnecessarily high rate of unemployment.

\section{Notes}

1 I have benefited greatly from discussions with Alexander Cappelen in preparing this article. I have also benefitted greatly from two anonymous referee reports.

2 That the egalitarian and liberal intuitions enjoy widespread support is evident from political debates, surveys, and economic experiments. Examples of surveys are: Schokkaert and Devooght (2003), Gaertner and Schwettmann (2007); examples of economic experiments are: Cappelen, Hole, Sørensen, and Tungodden (2007), Konow (2000), Frolich, Oppenheimer, and Kurki (2004).

3 For critical reviews of luck egalitarianism, see Anderson (1999), Scheffler (2003), and Fleurbaey (2001). 
4 This does now mean that there is a monotonic relationship between how many factors people are responsible for and the level of redistribution. At the outset it seems reasonable that the ideal level of redistribution is lower if people are held responsible for more factors. More responsibility should, in other words, imply more redistribution. However, A. Cappelen and B. Tungodden (2005) have shown that this is not necessarily the case, and that there will be situations in which increased responsibility results in the need for more redistribution.

5 In Chapter 7 of Sovereign Virtue, Dworkin (2000) explicitly argues that since people are responsible for their personality traits welfare should not be deemed an appropriate basis for interpersonal comparisons.

6 Equality of welfare is the ideal that people, independent of their choices, should be left with the same level of welfare, given some appropriate conception of welfare, such as happiness or preference satisfaction. Utilitarianism, on the other hand, asks which tax and welfare schemes would maximize the sum total of utility in a society, founded on some suitable conception of what utility is like, such as happiness, pleasure, or preference satisfaction. It then chooses, as the just allocation, precisely the allocation which maximizes total utility. Therefore, if preference-satisfaction were chosen as the suitable conception of utility, income and wealth would be distributed so as to maximize preference-satisfaction. The welfare function of such a principle has a specific theoretical form: it involves choosing the distribution that maximizes the arithmetic sum of all satisfied preferences (unsatisfied preferences being negative), weighted for the intensity of those preferences.

7 Arneson explicitly uses the control notion: «When a person enjoys equal opportunity for welfare [...] any actual inequality of welfare in the positions they reach is due to factors that lie within each individual's control. Thus, any such inequality will be non-problematic from the standpoint of distributive equality.» (Arneson 1989, p. 86) For all practical purposes, Arneson's and Cohen's cuts are identical, even though they use slightly different terminology.

8 Cohen uses the notion control interchangeably with that of choice (see e.g., Cohen 1989, p. 922).

9 For alternative criticisms, see for example Scheffler (2003) and Fleurbaey (2008).

10 Two factors cause inequalities in the unemployment example. The first factor, whether or not people work, is a non-responsibility factor given the assumption that the unemployment is involuntary. The second factor, people's work preferences (i.e., the amount of psychological well-being people receive from work versus non-work), is a responsibility factor according to Dworkin (given that people identify with their work preferences and are glad they have them). But since people are assumed to be identical with respect to this factor, i.e., they all prefer to work, it does not cause welfare inequalities. Dworkin cannot therefore, as in the example with the photographer, point to differences in a responsibility factor (e.g., some prefer work to nonwork, others non-work to work) in order to justify inequalities in welfare.

\section{Literature}

Anderson, E.S. (1999) What is the point of equality? Ethics, 109 (2), pp. 287-337.

Arneson, R. (1989) Equality and equal opportunity for welfare. Philosophical Studies, 56 (1), pp. 77-93. 
Arneson, R.J. (1990). Liberalism, distributive subjectivism, and equal opportunity for welfare. Philosophy and Public Affairs, 19 (2), pp. 158-194.

Atkinson, A. \& Micklewright, J. (1991) Unemployment compensation and labor transitions: A critical review. Journal of Economic Literature, 29, pp. 1679-1727.

Cappelen, A.W., Hole, A.D., Sørensen, E.Ø. \& Tungodden, B. (2007) The pluralism of fairness ideals: An experimental approach. American Economic Review, 97 (3), pp. 818-827.

Cappelen, A. \& Tungodden, B. (2005) Politics, philosophy and economics, 5 (10), pp. 353-362.

Carens, J. (2000) Culture, citizenship, and community. Oxford: Oxford University Press.

Classen, K.P. (1979) Unemployment insurance and job search. In Studies in the economics of search, eds. S.A. Lippman \& J.J. McCall, pp. 191-219. Amsterdam: North-Holland.

Cohen, G.A. (1989) On the currency of egalitarian justice. Ethics, 99 (4), pp. 906944.

Dunn, J. (1990) Reconceiving the content and character of modern political community. In Interpreting political responsibility, ed. J. Dunn, pp. 193-215. Oxford: Polity Press.

Dworkin, R. (1981a) What is equality? Part 1: Equality of resources. Philosophy and Public Affairs, 10 (3), pp. 185-246.

Dworkin, R. (1981b) What is equality? Part 2: Equality of resources. Philosophy and Public Affairs, 10 (4), pp. 283-345.

Dworkin, R. (2000) Sovereign virtue. Cambridge, MA: Harvard University Press.

Fleurbaey, M. (1995) Three solutions to the compensation problem. Journal of Economic Theory, 6, pp. 96-106.

Fleurbaey, M. (2001) «Egalitarian Opportunities» Law and Philosophy, 20, pp. 499530.

Fleurbaey, M. (2008) Fairness, responsibility and welfare. Oxford: Oxford University Press.

Frohlich, N., Oppenheimer, J. \& Kurki, A. (2004) Modeling other-regarding preferences and an experimental test. Public Choice, 119 (1-2), pp. 91-117.

Gallie, D. \& Russell, H. (1998) Unemployment and life satisfaction. Archives Européennes de Sociologie, 39 (2), pp. 3-35.

Gaertner, W. \& Schwettmann, L. (2007) Equity, responsibility and the cultural dimension. Economica, 74 (296): 627-649.

Konow, J. (2000) Fair shares: Accountability and cognitive dissonance in allocation of decisions. American Economic Review, 90 (4), pp. 1072-1091.

Krueger, A. \& Meyer, B. (2002) Labor supply effects of social insurance. In Handbook of public economics, eds. A. Auerbach \& M. Feldstein, vol 4, pp. 2327-2392. Amsterdam: North-Holland.

Roemer, J.E. (1993) A pragmatic theory of responsibility for the egalitarian planner. Philosophy and Public Affairs, 22 (22), pp. 146-166.

Roemer, J.E. (1996) Theories of distributive justice. Cambridge, MA: Harvard University Press.

Scheffler, S. (2003) What is egalitarianism? Philosophy \& Public Affairs, 31 (1), pp. 5-39.

Schokkaert, E. \& Devooght, K. (2003) Responsibility-sensitive fair compensation in different cultures. Social Choice and Welfare, 21 (2), pp. 207-242. 
Solon, G.R. (1985) Work incentive effects of taxing unemployment benefits. Econometrica, 53 (2), pp. 295-306.

Warr, P.B. (1987) Work, unemployment and mental health. Oxford: Clarendon Press.

Whelan, C.T., Hannon, D.F. \& Creighton, S. (1991) Unemployment, poverty and psychological distress. Dublin: Economic and Social Resource Institute. 